\title{
Kinetic analysis of the polymer burnout in ceramic thermoplastic processing of the YSZ thin electrolyte structures using model free method
}

\author{
Mehdi Salehi $^{\mathrm{a}, \mathrm{b}, *}$, Frank Clemens ${ }^{\mathrm{a}}$, Thomas Graule ${ }^{\mathrm{a}}$, Bernard Grobéty ${ }^{\mathrm{b}}$ \\ ${ }^{a}$ Laboratory for High Performance Ceramics, Empa, Swiss Federal Laboratories for Materials Science and Technology, Ueberlandstrasse 129, CH-8600 Duebendorf, Switzerland \\ ${ }^{\mathrm{b}}$ The Fribourg Center for Nanomaterials (FriMat) and Department of Geosciences, University of Fribourg, Pérolles, Ch. du Musée 6, CH-1700 Fribourg, Switzerland
}

\begin{abstract}
Polymeric binder burnout during thermoplastic processing of yttria stabilized zirconia (YSZ) ceramics were analyzed using thermogravimetric analysis (TGA). The debinding kinetics of the stearic acid/polystyrene binder have been described using model free methods and compared with the decomposition rate of the pure polymers. The apparent activation energy $E_{\alpha}$ as a function of debinding progress $\alpha$ was calculated in two atmospheres (argon and air) by three different methods: Ozawa-Flynn-Wall (OFW), Kissinger-Akahira-Sunose (KAS) and Friedman. The evolution of $E_{\alpha}$ with $\alpha$ is compatible with the evaporation of stearic acid and the unzipping and thermo-oxidative decomposition mechanisms proposed for polystyrene. The apparent activation energies obtained for the experiments under argon revealed the increased concentration of weak links in polystyrene introduced during kneading of the feedstock. Extrapolation of the kinetic parameters obtained in one run to calculate decomposition rates under different heating rates confirmed the excellent predictive power of the direct methods.
\end{abstract}

\section{Introduction}

Global warming and declining fossil fuel reserves has intensified research in clean energy such as fuel cell technology. Solid oxide fuel cells (SOFCs) are electrochemical devices which directly produce electrical energy by oxidizing a fuel such as hydrogen, diesel and natural gas with high efficiency and low pollution emissions [1]. Owing to its thermal and chemical stability as well as its high ionic conductivity over a wide range of operating conditions, yttria-stabilized zirconia (YSZ) is used as the solid electrolyte at the elevated temperature for SOFCs [2-5]. To prevent cross flow and to maintain the chemical potential between anode and cathode, the electrolyte has to be gas tight, but should also be as thin as possible in order to reduce ohmic losses [6,7]. Both planner and tubular designs have been used [8-15].Thermoplastic processing such as extrusion and injection molding are the most promising manufacturing technique to obtain thin-walled, yet impermeable tubular structures $[9,11,13]$.

During thermoplastic processing, the polymer provides the plasticity necessary during the shaping process and guarantees sufficient mechanical strength for further handling of the fragile

\footnotetext{
* Corresponding author at: Laboratory for High Performance Ceramics, Empa Swiss Federal Laboratories for Materials Science and Technology, Ueberlandstrasse 129, CH-8600 Duebendorf, Switzerland. Tel.: +41 58765 4952; fax: +41 58765 4150.

E-mail addresses: Mehdi.Salehi@empa.ch, chemehdi3333@gmail.com (M. Salehi).
}

tubular green bodies. The most critical step is the polymer burnout, or so-called "debinding". The release of large volumes of volatile decomposition products can lead to blister and crack formation, as well as to deformation of the specimen.

The debinding time-temperature cycle is often adjusted through a "trial and error" procedure for each system. To avoid such a time consuming experimental determination of the optimal debinding procedure, a better understanding of the polymer decomposition mechanism is necessary. The rate and the activation energy of the individual reaction and transport processes involved are key parameters to model the polymer removal and to optimize the debinding process.

Transport and elementary reaction steps are possible rate limiting processes during debinding of a green body. Heat is transported into and mass transported out of the sample, through already emptied pore space, across the interface with the binder as well as through the molten polymer and vice versa (Fig. 1). For experiments under air, a reactant, oxygen, is transported into the sample. In the early stages of debinding, mass transport is mainly capillary and pressure driven liquid transport, which is followed by diffusive/convective gas transport through the melt and the open pores [16-18].

The decomposition mechanisms of polymers are usually complex with several parallel and sequential reaction steps and each of them can be rate limiting. Low molecular weight polymers may evaporate before reaching the decomposition temperature.

Which of the main processes, transport or reaction is rate limiting depends mainly on the size of the sample. For sample 


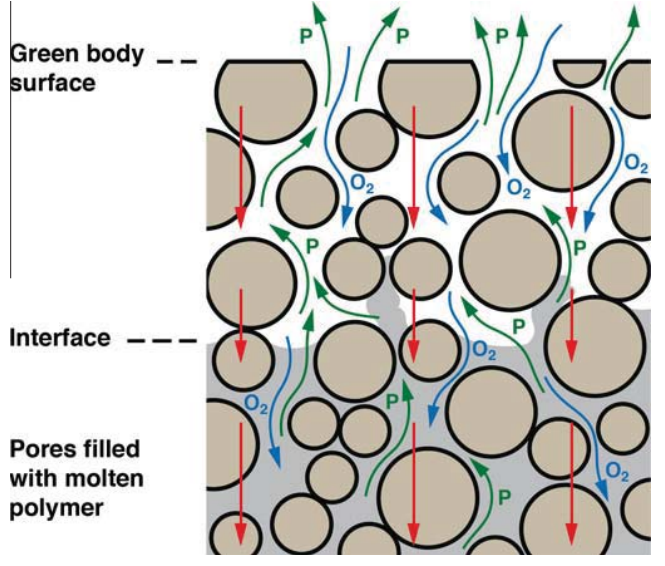

Fig. 1. Transport processes during debinding (model based on the planar binder front): transport of heat (red colored arrows) and convection/diffusion of matter i.e. polymer melt (capillary flow, gray arrow) evaporated polymer molecules or decomposition species (green colored arrows) and oxygen (blue colored arrows). Three transport zones can be distinguished: through open pores, across the interface and through polymer filled pores. (For interpretation of the references to color in this figure legend, the reader is referred to the web version of the article.)

dimensions $>1 \mathrm{~mm}$, transport is usually rate limiting, whereas for thinner samples, such as SOFC electrolyte membranes, polymer decomposition kinetics may take over [19].

The decomposition of polymers proceeds through heterogeneous reactions involving solids, liquids and gases. For heterogeneous solid-involving reactions, two different methods have been widely used to determine the kinetic parameters from thermoanalytical measurements: (1) model fitting methods and (2) model - free methods (or isoconversional method). An overview of the literature dealing with the kinetics of debinding shows that most of the authors used a model fitting methods [19-28].

The equations for the model fitting methods are derived from the underlying reaction mechanism(s) assumed to be rate determining. Vyazovkin and Wight demonstrated that model-fitting methods are not reliable procedures to determine the Arrhenius parameters [29-31], except when the reaction mechanism is known in details. The latter, however, is in general more complex than contained in the individual models. Moreover, Criado and Morales [32] pointed out that a single alpha against $T$ curve recorded at a certain heating rate can be described by different kinetic triplets. The inherent experimental errors do not allow to discriminate between the various kinetic triplet used.

Most solid state reactions are composed of many reaction steps. The activation energy usually changes with reaction progress, and the rate-determining steps can usually not been determined from the kinetic analysis alone. Vyazovkin and Lesnikovich [33] recognized, however, that the overall reaction style is reflected in the dependency of the activation energy on reaction progress. They distinguished processes with prevalent competing $[33,34]$, independent [35], reversible [34], and sequential [35] reaction steps as well as reactions complicated by diffusion [33,36]. Model-free methods turn out to be the most reliable way to determine kinetic parameters of thermally activated complex processes, because the prior knowledge of the reaction mechanism is not necessary. The application of these methods requires a series of non-isothermal experiments performed under different heating rates.

In this study, we used model free methods to study the thermal decomposition of the polymer mixture present in thin thermoplastic green bodies of yttrium stabilized zirconia (YSZ) and to compare it with the thermal behavior of pure polymer. The thickness of the samples is similar to the ones of the components used as electrolyte in SOFC cells. It is expected that the binder removal rate for such thin samples is only be determined by the decomposition rate of the polymer and not by transport processes. We applied different model free methods to test their consistency and their potential as predictive tool.

\section{Experimental procedure}

\subsection{Materials}

The feedstock contained 85.22 wt.\% of yttria-stabilized zirconia powder (Tosoh TZ-8YS, Krahn Chemie, Germany) mixed with 10.85 wt.\% of polystyrene (PS, type 648 , Dow Company, Switzerland) as binder and $3.93 \mathrm{wt} . \%$ of stearic acid (SA) added as a surfactant (Fluka AG, Switzerland).

The particle size distribution of the powder was measured by laser diffraction (LS230, Beckman-Coulter, USA) in a water suspension. The specific surface area (SSA) of the powder was determined from a five-point $\mathrm{N}_{2}$ adsorption isotherm obtained from BET measurements (Beckman-Coulter SA3100, Beckman-Coulter, USA). The density of the powder was measured by He-pycnometer (Micromeritics, AccuPyc 1330, USA). According to the analysis, the average particle size of the TZ-8YS is $0.50 \mu \mathrm{m}$, the density is $6.1 \mathrm{~g} / \mathrm{cm}^{3}$, and specific surface area is $6.5 \mathrm{~m}^{2} / \mathrm{g}$.

\subsection{Preparation of the sample}

The feedstock (ceramic-polymer composite, in the following labeled Z-85 $=85.22$ wt.\% of $\mathrm{ZrO}_{2}$ ) was prepared with a high shear mixer (HAAKE PolyLab Mixer, Rheomix 600, Thermo Scientific). The mixing chamber $\left(69 \mathrm{~cm}^{3}\right)$ was filled to $70 \%$ of the total volume. The mixing was carried out using a two-step sequence: in the first step, the mixing was performed at $10 \mathrm{rpm}$ and $170^{\circ} \mathrm{C}$ for $30 \mathrm{~min}$ and subsequently at $10 \mathrm{rpm}$ and $150^{\circ} \mathrm{C}$ min until the mixing torque stabilized (ca. $150 \mathrm{~min}$ ). Samples of pure polystyrene were treated the same way as the first mixing step $\left(\mathrm{PS}_{\text {kneading }}=\right.$ kneading pure PS at $170^{\circ} \mathrm{C}$ ). For thermogravimetric analysis, disk samples were produced by warm pressing. Feedstock was loaded into a steel die with heating mantle and uniaxially pressed at $30 \mathrm{kN}$ and $165^{\circ} \mathrm{C}$ for $30 \mathrm{~min}$.

\subsection{Thermogravimetric analysis (TGA)}

The TGA (TGA/SDTA851e, Mettler-Toledo, Switzerland) runs from 30 to $600{ }^{\circ} \mathrm{C}$ were carried out with four different linear heating rates $\left(10,15,20\right.$ and $\left.30^{\circ} \mathrm{C} / \mathrm{min}\right)$. The samples were placed in open aluminum crucible $(150 \mu \mathrm{L})$. All TGA analyses were made in air or in argon (99.999\%) atmosphere with a flow rate of $50 \mathrm{~cm}^{3}$ / min. SA and PS pellets (untreated PS and PS kneaded at $170{ }^{\circ} \mathrm{C}$ ) of around $4 \mathrm{mg}$ as well as Z-85 disk samples (uniaxially pressed at $30 \mathrm{kN}$ and $165^{\circ} \mathrm{C}$ for $30 \mathrm{~min}$ ) with a thickness of $0.7 \mathrm{~mm}$ and total weight of around $30 \mathrm{mg}$ were used for the TGA investigations. The buoyancy effect in TGA has been taken into account by carrying out empty crucible runs and subtracting the resulting weight differences from the subsequent sample mass loss data [37]. Repeatability of the TGA experiments showed an uncertainty of $\pm 2{ }^{\circ} \mathrm{C}$.

The conversion or normalized mass loss was determined as:

$\alpha=\frac{m_{\text {sample }}^{0}-m_{\text {sample }}(T, t)}{m_{\text {sample }}^{0}-m_{\text {sample }}^{\infty}}$

where $m_{\text {sample }}^{0}$ is the initial sample mass, $m_{\text {sample }}^{\infty}$ is the final sample mass after the non-isothermal runs, $m_{\text {sample }}(T, t)$ represents the mass of the sample at arbitrary temperature $T$ (or time $t$ ). The apparent activation energies have been determined using the Kissinger, KAS, OFW and FR methods (Table 1). Data for conversions 
ranging from $5 \%$ to $95 \%$ with step size of $5 \%$ were used for the calculation of the activation energy.

\section{Model free methods}

The thermal decomposition of polymeric materials can be described by the following general reaction:

$A($ Solid/Liquid $) \rightarrow B($ Solid/Liquid $)+C($ Volatile $)$

The rate of decomposition, $\frac{d \alpha}{d t}$, for isothermal reactions may be expressed by:

$\frac{d \alpha}{d t}=k(T) f(\alpha)$

where $f(\alpha)$ is a function describing the reaction mechanism, $\alpha$ is the reacted fraction of $A$ in Eq. (2) or the extent of conversion, and $k$ is the rate constant at temperature $T$. The temperature dependence of the rate constant is given by the Arrhenius equation:

$k(T)=A \exp \left(-\frac{E}{R T}\right)$

where $A$ is the pre-exponential factor, $E$ is the activation energy and $R$ is the universal gas constant.

Eq. (3) can be re-written for non-isothermal experiments done with a linear heating rate, $\beta=\frac{d T}{d t}$, by:

$\frac{d \alpha}{d T}=\frac{A}{\beta} \exp \left(-\frac{E}{R T}\right) f(\alpha)$

where $d \alpha / d T$ is the non-isothermal reaction rate $[38,39]$.

The rate equations can be solved for the activation energy and the pre-exponential factor if and only if the function $f(\alpha)$ is known and remains constant for the entire duration of the reaction, which is rarely the case for solid state reactions.

An alternative approach is based on the isoconversional principle stating that the reaction rate for a given reaction progress is only a function of temperature:

$\frac{d \ln (d \alpha / d t)}{d T^{-1}}=-\frac{E}{R}$

The Kissinger method [40] is based on the solution of the rate equation when the reaction rate is at the maximum, i.e. $\frac{d}{d t}\left(-\frac{d \alpha}{d t}\right)=0$. The initial equation proposed by Kissinger was not model free but for $n$th order reactions $\left(f(\alpha)=(1-\alpha)^{n}\right)$, which introduced into Eq. (5) give:

$\frac{E \beta}{R T_{\max }^{2}}=A\left(n\left(1-\alpha_{\max }\right)^{n-1}\right) \exp \left(-\frac{E}{R T_{\max }}\right)$

For a first order reaction, i.e. $f(\alpha)=(1-\alpha)$ and $f^{(\alpha)}=-1$ Eq. (5) results in: $\frac{\ln \beta}{T_{\max }^{2}}=\frac{\ln A R}{E}-\frac{E}{R T_{\max }}$

Kissinger himself $[40,41]$ and several authors have shown that for a constant heating rate the value of $\alpha_{m}$ is nearly independent of the heating rate and the $\frac{E}{R T_{\max }}$ values extracted from $\frac{\ln \beta}{T_{\max }^{2}}$ vs. $\frac{1}{R T_{\max }}$ plots are independent of the model chosen, turning the Kissinger method for these conditions to a model-free method. The Kissinger method is, however, not isoconversional i.e. the activation energy cannot be determined for any reaction progress but only for $\alpha_{m}$.

The other three methods are isoconversional, i.e. the activation energy can be determined for any reaction progress, even when the function $f(\alpha)$ is not known. The Ozawa-Flynn-Wall (OFW) $[42,43]$ and Kissinger-Akahira-Sunose (KAS) [41,44] methods are derived from the integral form of the non-isothermal rate Eq. (5):

$g(\alpha)=\frac{A}{\beta} \int_{0}^{T} e^{-\frac{E_{a}}{R T}} d T$

This integral, also called the "temperature integral" in the kinetic literature, has no analytical solution, but several approximations having been proposed [45-47]. The OFW method uses the Doyle approximation [48]. Taking the common logarithm of Eq. (5) and substituting Doyle's approximation gives the following linear relationship:

$\log \beta=\log \frac{A E_{a}}{g(\alpha) R}-2.315-0.457 \frac{E_{a}}{R T}$

and the activation energy can be obtained from the slope of plots $\log \beta$ vs. $\frac{1}{R T}$ at the conversion of interest. The KAS method uses the Murray and White approximation, later refined by Coats and Redfern as well as by Senum and Yang $[44,49,56]$. These approximations are more accurate than the Doyle approximation. Using the Murray and White approximation for the solution of the temperature integral results in:

$\ln \frac{\beta}{T^{2}}=\ln \frac{\mathrm{AR}}{\mathrm{EG}(\alpha)}-\frac{E}{R T}$

Plot $\ln \frac{\beta}{T^{2}}$ vs. $\frac{1}{R T}$ enables the determination of the activation energy from the slope for the selected degree of conversion.

The Friedman method [50] is a isoconversional method based on the logarithmic version of the rate equation (Eq. (3)):

$\ln \left(\frac{d \alpha}{d T}\right)=\ln \left(\frac{A}{\beta} f(\alpha)\right)-\frac{E}{R T}$

Pairs of $\left(\frac{d \alpha}{d t}\right)_{\alpha i}$ and $T_{\alpha i}$, determined for a specific $\alpha$ in a series of experiments with different heating rates $\beta_{i}$, plotted in a diagram $\ln \left(\frac{d \alpha}{d t}\right)$ vs. $\frac{1}{R T}$ allows to extract the activation energy for the given $\alpha$.

There is usually a difference between the activation energies obtained by the Friedman method and the integral (OFW and KAS) methods. It has been shown that the causes for these differences between the integral and differential methods are due to their

Table 1

Model free methods used for calculation of apparent activation energy.

\begin{tabular}{|c|c|c|c|}
\hline Method & Expression & Plots & Refs. \\
\hline Kissinger & $\ln \frac{\beta}{T_{\max }^{2}}=\left\{\ln \frac{A R\left(n\left(1-\alpha_{\max }\right)^{n-1}\right)}{E}\right\}-\frac{E}{R T_{\max }}$ & $\ln \frac{\beta}{T_{\max }^{2}}$ vs. $\frac{1}{R T_{\max }}$ & [40] \\
\hline Ozawa-Flynn-Wall & $\log \beta=\log \left(\frac{A E}{\operatorname{Rg}(\alpha)}\right)-2.315-0.4657 \frac{E}{R T}$ & $\log \beta$ vs. $\frac{1}{R T}$ & {$[42,43]$} \\
\hline Kissinger-Akahira-Sunose & $\ln \frac{\beta}{T^{2}}=\ln \frac{\mathrm{AR}}{\mathrm{EG}(\alpha)}-\frac{E}{R T}$ & $\ln \frac{\beta}{T^{2}}$ vs. $\frac{1}{R T}$ & {$[40,44]$} \\
\hline Friedman & $\ln \frac{d \alpha}{d t}=\ln (A f(\alpha))-\frac{E}{R T}$ & $\ln \left(\frac{d \alpha}{d t}\right)$ vs. $\frac{1}{R T}$ & [50] \\
\hline
\end{tabular}



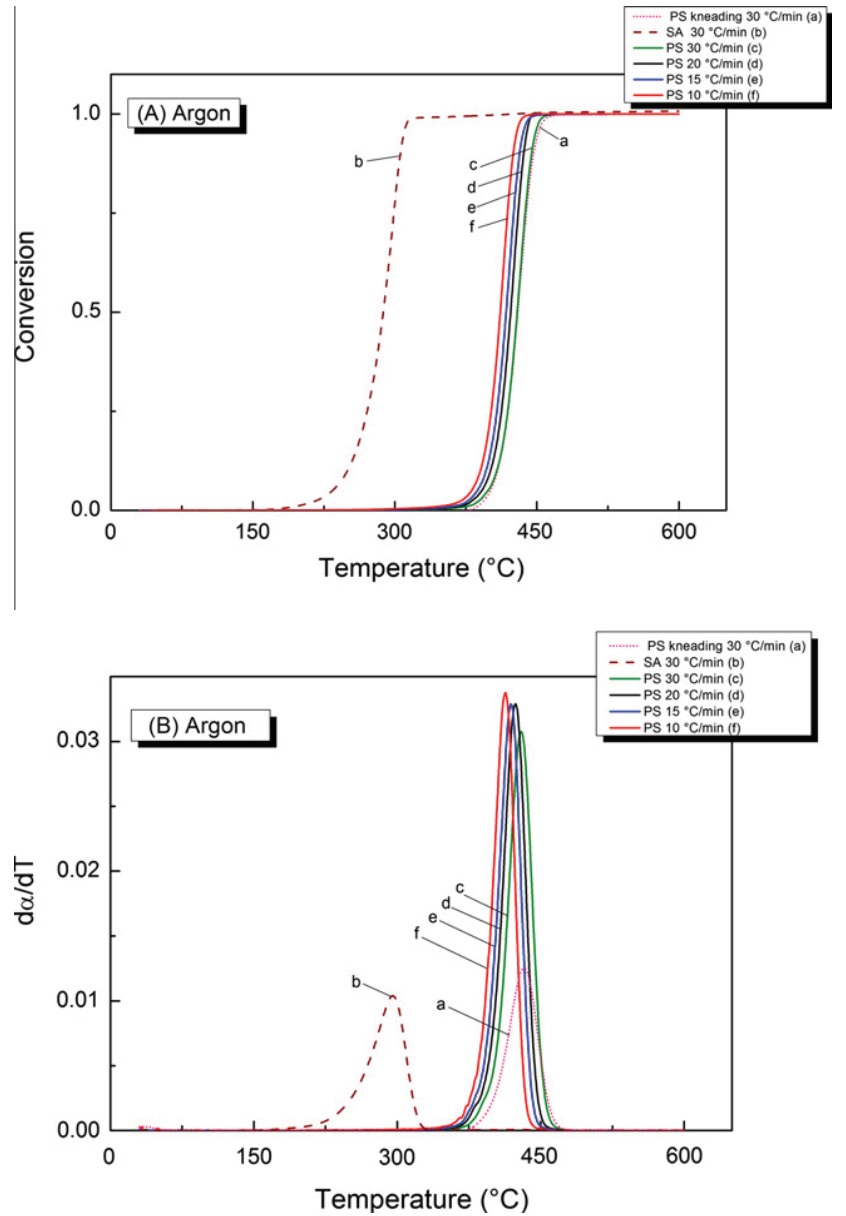

Fig. 2. (A) Extent of conversion and (B) conversion rate (DTG plot) vs. temperature for PS, PSkneading and SA at different heating rates in argon atmosphere. (a) PS kneading at $30^{\circ} \mathrm{C} / \mathrm{min}$, (b) SA at $30^{\circ} \mathrm{C} / \mathrm{min}$, (c-f) pure PS at different heating rates $\left(10,15,20\right.$, and $\left.30^{\circ} \mathrm{C} / \mathrm{min}\right)$, respectively.

intrinsic nature [51-54]. The approximations of temperature integral are obtained under the assumption that the activation energy does not depend on the degree of conversion. For multistep processes, this is clearly not the case and a systematic error in the calculation, in particular for OFW method [55], will be introduced. For reactions, which show only moderate in/decrease of $E$ with $\alpha$, the deviations are usually less than $10 \%$ between the OFW/KAS and Friedman method [30,31]. The Friedman method is not based on any assumption $[51,53]$. However, the Friedman method has a tendency to be more sensitive to experimental noise. This problem can be overcome by proper smoothing of the data before carrying out the Friedman method.

\section{Prediction from non-isothermal model-free analysis}

Starting from a single non-isothermal experiment, the model free isoconversional methods provide a procedure to extrapolate to other heating rates and temperatures, assuming that the kinetic triplet, i.e. pre-exponential factor, activation energy and rate limiting step for a given extent of conversion are independent of heating rate and temperature, at which the conversion is reached. Under this condition non-isothermal rate equations for different heating rates $\beta$ and $\beta_{0}$, but the same extent of conversion $(\alpha)$, can be equated [34]:
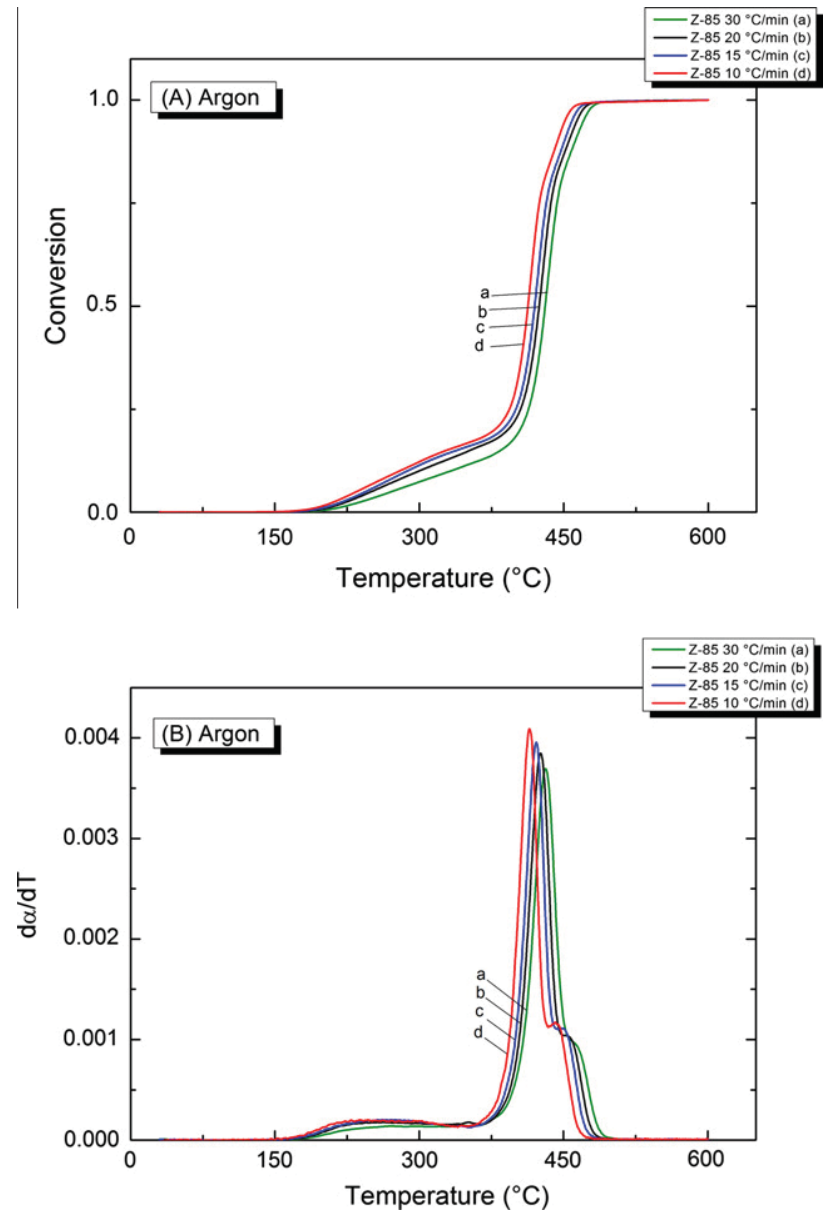

Fig. 3. (A) Extent of conversion and (B) conversion rate (DTG plot) vs. temperature for Z-85 at different heating rates in argon atmosphere. (a-d) Z-85 at different heating rates $\left(10,15,20\right.$, and $\left.30^{\circ} \mathrm{C} / \mathrm{min}\right)$, respectively.

$\left(\frac{1}{\beta}\right) \int_{0}^{T_{\alpha}} \exp \left(\frac{-E_{\alpha}}{R T}\right) d T-\left(\frac{1}{\beta_{0}}\right) \int_{0}^{T_{\alpha_{0}}} \exp \left(\frac{-E_{\alpha}}{R T}\right) d T=0$

where $T_{\alpha}$ and $E_{\alpha}$ are experimental values of the temperature and activation energy, respectively; $T_{\alpha 0}$, obtained as solution of (Eq. (13)) is the temperature at which the same conversion will be reached at the arbitrary heating rate $\beta_{0}$. Solving Eq. (13) for different conversions, the dependency of $\alpha$ on $T$ at an arbitrary heating rate can be predicted. To solve the temperature integrals in Eq. (13) the fourth order approximation given by Senum and Yang [56] was used. The average relative deviation (ARD) was calculated by the following equation:

$\operatorname{ARD}(\%)=\left(\frac{100}{N}\right) \sum_{i=1}^{N}\left|\frac{T_{\alpha}^{\text {exp }}-T_{\alpha}^{\text {pre }}}{T_{\alpha}^{\text {exp }}}\right|$

where $N$ is the number of data points for each experiment, $T_{\alpha}^{\exp }$ is the experimental value of the temperature at a given conversion and $T_{\alpha}^{\text {pre }}$ is the predicted temperature at a given conversion.

\section{Results and discussion}

\subsection{Thermal analysis}

\subsubsection{Thermal analysis in argon atmosphere}

The extent of conversion as well as the conversion rate as the function of temperature and heating rate for PS, PS $_{\text {kneading, }}$ SA and 
Table 2

Non- isothermal TGA results for PS and Z-85 samples in argon atmosphere.

\begin{tabular}{lllllll}
\hline Sample & $\begin{array}{l}\text { Heating rate } \\
\left({ }^{\circ} \mathrm{C} / \mathrm{min}\right)\end{array}$ & $\begin{array}{l}T_{\text {onset }} \\
\left({ }^{\circ} \mathrm{C}\right)\end{array}$ & $\begin{array}{l}T_{m} \\
\left({ }^{\circ} \mathrm{C}\right)\end{array}$ & $\begin{array}{l}\alpha_{m} \\
(\%)\end{array}$ & $\begin{array}{l}T_{\text {onset }}^{o} \\
\left({ }^{\circ} \mathrm{C}\right)\end{array}$ & $\begin{array}{l}T_{m}^{o} \\
\left({ }^{\circ} \mathrm{C}\right)\end{array}$ \\
\hline Pure PS & 10 & 394.06 & 414.82 & 61.4 & 387.80 & 407.49 \\
& 15 & 399.40 & 420.78 & 60.3 & & \\
& 20 & 407.90 & 425.74 & 61.1 & & \\
$\mathrm{PS}_{\text {kneading }}$ & 30 & 409.86 & 432.03 & 58.6 & & \\
$\mathrm{SA}$ & 30 & 408.39 & 433.61 & 59.2 & & \\
$\mathrm{Z}-85$ & 10 & 254.90 & 295.45 & 64.5 & & \\
& 15 & 392.54 & 416.97 & 59.7 & 387.22 & 410.26 \\
& 20 & 398.48 & 423.34 & 58.1 & & \\
& 30 & 401.06 & 428.12 & 57.9 & & \\
\hline
\end{tabular}

$T_{\text {onset }}$ : onset temperature, $T_{m}$ : temperature DTG peak, $\alpha_{m}$ : conversion correspond to the temperature DTG peak, and $T_{\text {onset }}^{o}, T_{m}^{o}$ : extrapolated values to the heating rate of $0{ }^{\circ} \mathrm{C} / \mathrm{min}$.
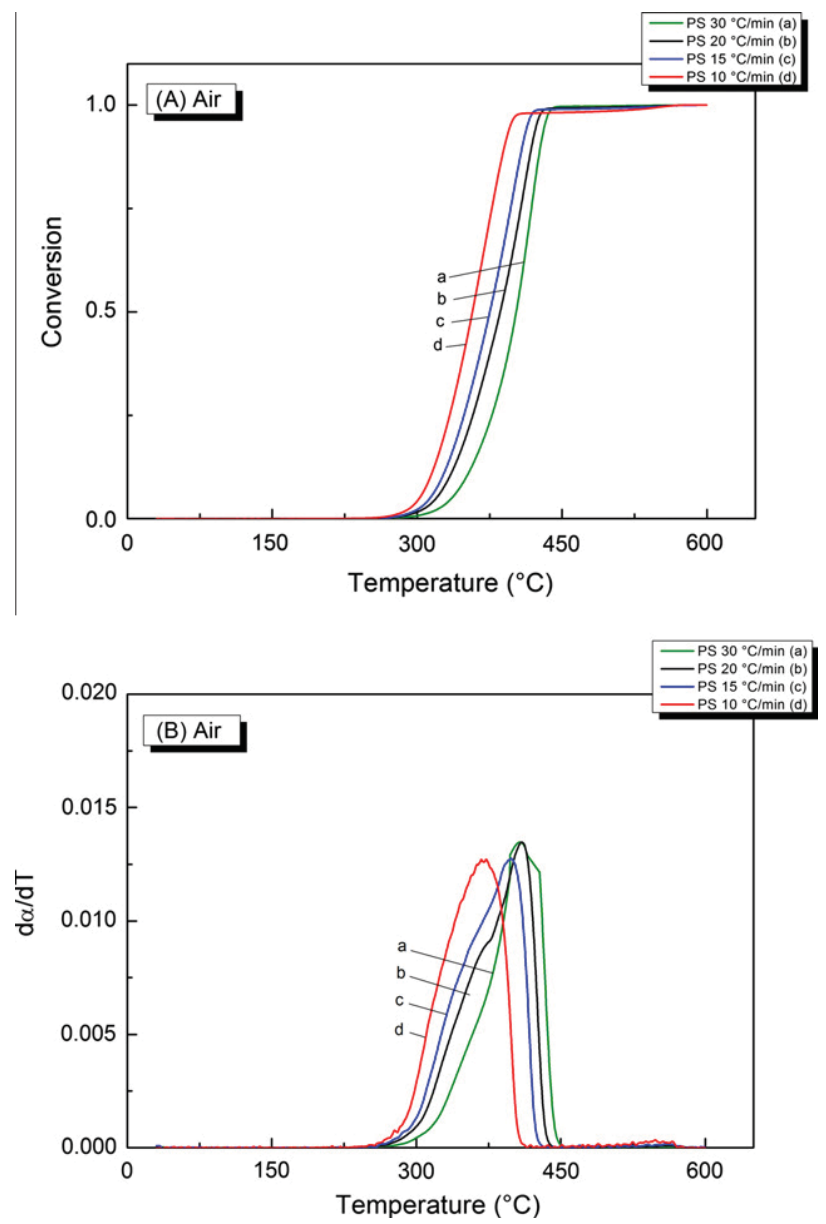

Fig. 4. (A) Extent of conversion and (B) conversion rate (DTG plot) vs. temperature for PS at different heating rates in air atmosphere. (a-d) Pure PS at different heating rates $\left(10,15,20\right.$, and $\left.30^{\circ} \mathrm{C} / \mathrm{min}\right)$, respectively.

Z-85 samples in argon atmosphere at different heating rates are presented in Figs. 2 and 3, respectively. The instantaneous mass loss has been normalized by the total loss.

The temperature at the decomposition onset ( $\left.T_{\text {onset }}\right)$ and the temperature at which the maximum mass loss rate is observed $\left(T_{m}\right)$ and the corresponding degree of conversion $\left(\alpha_{m}\right)$ have been determined from Figs. 2 and 3 and are presented in Table 2. It is evident from Table 2 that these characteristic temperatures increase with increasing heating rate. Equilibrium $T_{m}\left(T_{m}^{o}\right)$ and
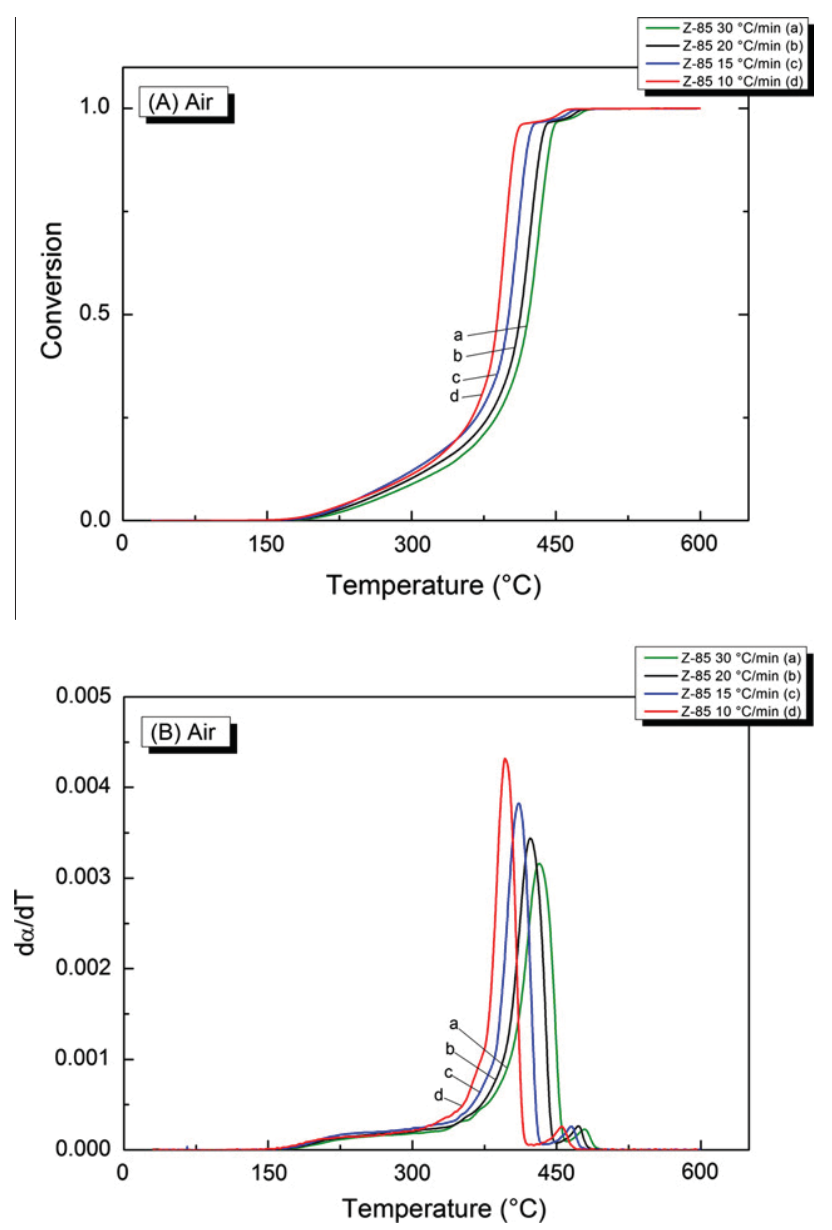

Fig. 5. (A) Extent of conversion and (B) conversion rate (DTG plot) vs. temperaturure for Z-85 at different heating rates in air atmosphere. (a-d) Z-85 at different heating rates $\left(10,15,20\right.$, and $\left.30^{\circ} \mathrm{C} / \mathrm{min}\right)$, respectively.

Table 3

Non-isothermal TGA results for PS and Z-85 samples in air atmosphere.

\begin{tabular}{cllllll}
\hline Sample & $\begin{array}{l}\text { Heating rate } \\
\left({ }^{\circ} \mathrm{C} / \mathrm{min}\right)\end{array}$ & $\begin{array}{l}T_{\text {onset }}^{o} \\
\left({ }^{\circ} \mathrm{C}\right)\end{array}$ & $\begin{array}{l}T_{m} \\
\left({ }^{\circ} \mathrm{C}\right)\end{array}$ & $\begin{array}{l}\alpha_{m} \\
(\%)\end{array}$ & $\begin{array}{l}T_{\text {onset }}^{o} \\
\left({ }^{\circ} \mathrm{C}\right)\end{array}$ & $\begin{array}{l}T_{m}^{o} \\
\left({ }^{\circ} \mathrm{C}\right)\end{array}$ \\
\hline Pure PS & 10 & 322.90 & 367.45 & 62.7 & 297.92 & 356.71 \\
& 15 & 335.28 & 398.61 & 77.7 & & \\
& 20 & 351.76 & 410.72 & 79.7 & & \\
Z-85 & 30 & 373.55 & 417.27 & 73.3 & & \\
& 10 & 372.18 & 396.04 & 65.9 & 360.07 & 382.07 \\
& 15 & 378.10 & 410.53 & 70.6 & & \\
& 20 & 390.24 & 423.10 & 69.6 & & \\
\hline
\end{tabular}

$T_{\text {onset }}$ : onset temperature, $T_{m}$ : temperature DTG peak, $\alpha_{m}$ : conversion correspond to the temperature DTG peak, and $T_{\text {onset }}^{o}, T_{m}^{o}$ : extrapolated values to the heating rate of $0{ }^{\circ} \mathrm{C} / \mathrm{min}$.

$T_{\text {onset }}\left(T_{\text {onset }}^{o}\right)$ have been determined by extrapolating the measured values to an infinitely slow heating rate $\left(0^{\circ} \mathrm{C} / \mathrm{min}\right)$. These values are similar for PS and Z-85.

The decomposition for Z-85 starts at a lower temperature $\left(170^{\circ} \mathrm{C}\right)$ comparing to the untreated as well as kneaded PS $\left(350^{\circ} \mathrm{C}\right)$ (Fig. 2a vs. Fig. 3a). This translates into a larger degree of conversion attained for $T_{\text {onset }}$ in Z-85 in comparison with PS for all heating rates $\left(15^{\circ} \mathrm{C} / \mathrm{min}\right.$; PS $\left.\alpha_{\text {onset }}=12.71 \%, \mathrm{Z}-85 \alpha_{\text {onset }}=24.2 \%\right)$. Later the decomposition rate catches up in pure PS and at $T_{m}$, 

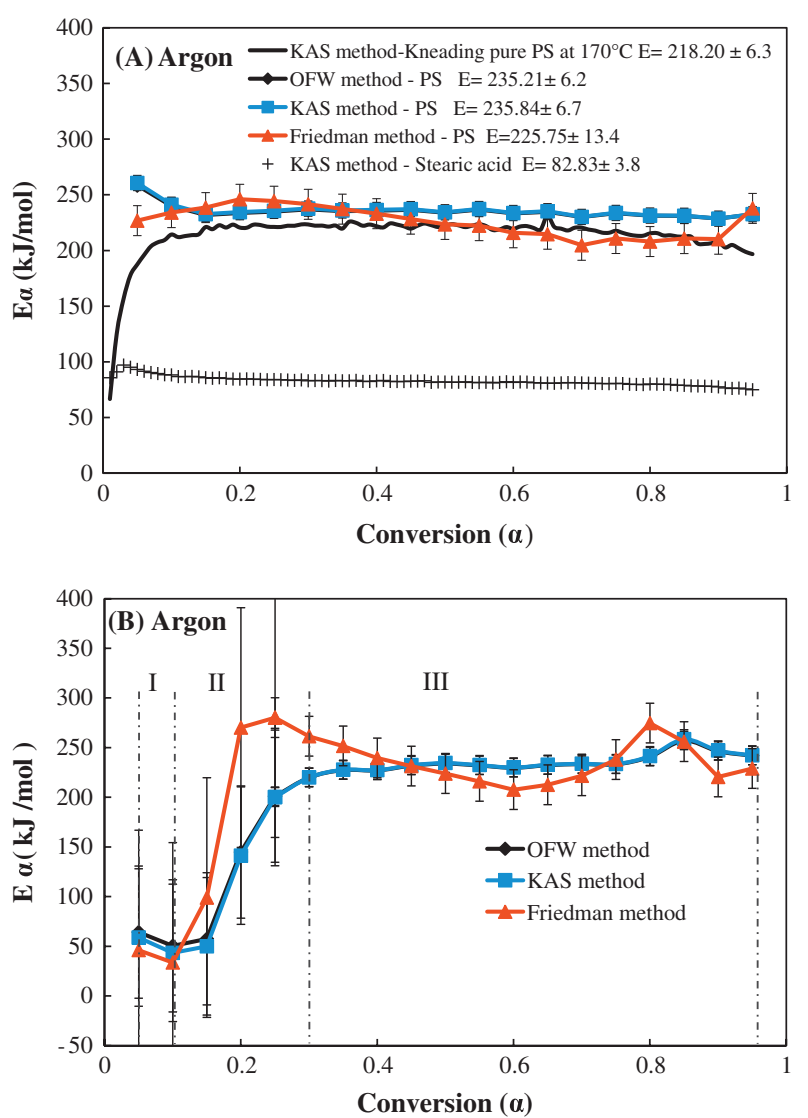

Fig. 6. The dependence of the apparent activation energy on the degree of the conversion for (A) pure PS, PSkneading and SA and (B) Z-85, using the model free methods in argon.

which is almost identical in both samples, the conversion attained is similar. Another difference in the evolution of the reaction rate can be observed towards the end of the reaction. The DTG curve of the Z-85 curve has a shoulder, which has not been observed for pure PS, i.e. the mass loss extends to higher temperatures.

\subsubsection{Thermal analysis in air}

The extent of conversion and conversion rate as function of temperature and heating rate for pure PS and feedstock samples in air are presented in Figs. 4 and 5, respectively.

Replacing argon by air caused a decrease of the characteristic temperatures ( $T_{\text {onset }}$ and $T_{m}$ ) and the maximum conversion rate $\left(\alpha_{m}\right)$ is observed at a higher value of $\alpha$ (Table 3). Similar results have been reported earlier [37,57-60]. For example, at a heating rate of $10^{\circ} \mathrm{C} / \mathrm{min}$, the onset temperature of pure PS is $72{ }^{\circ} \mathrm{C}$ lower compared to $T_{\text {onset }}$ observed during the experiment in argon (Tables 2 and 3). Moreover, the differences between the characteristic temperatures for pure PS and Z-85 are larger than in argon. The characteristic temperatures are also more sensitive to the heating rates, i.e., the shift of $T_{\text {onset }}$ and $T_{m}$ to higher temperatures with increasing heating rate is more pronounced under air than under argon.

\subsection{Decomposition kinetics and mechanisms}

The apparent activation energies have been extracted from the TGA experiments presented in the previous chapter using the OFW, KAS and Friedman method. The value of the activation energy $\left(E_{\alpha}\right)$ and its change with $\alpha$ is discussed in terms of PS and SA decomposition
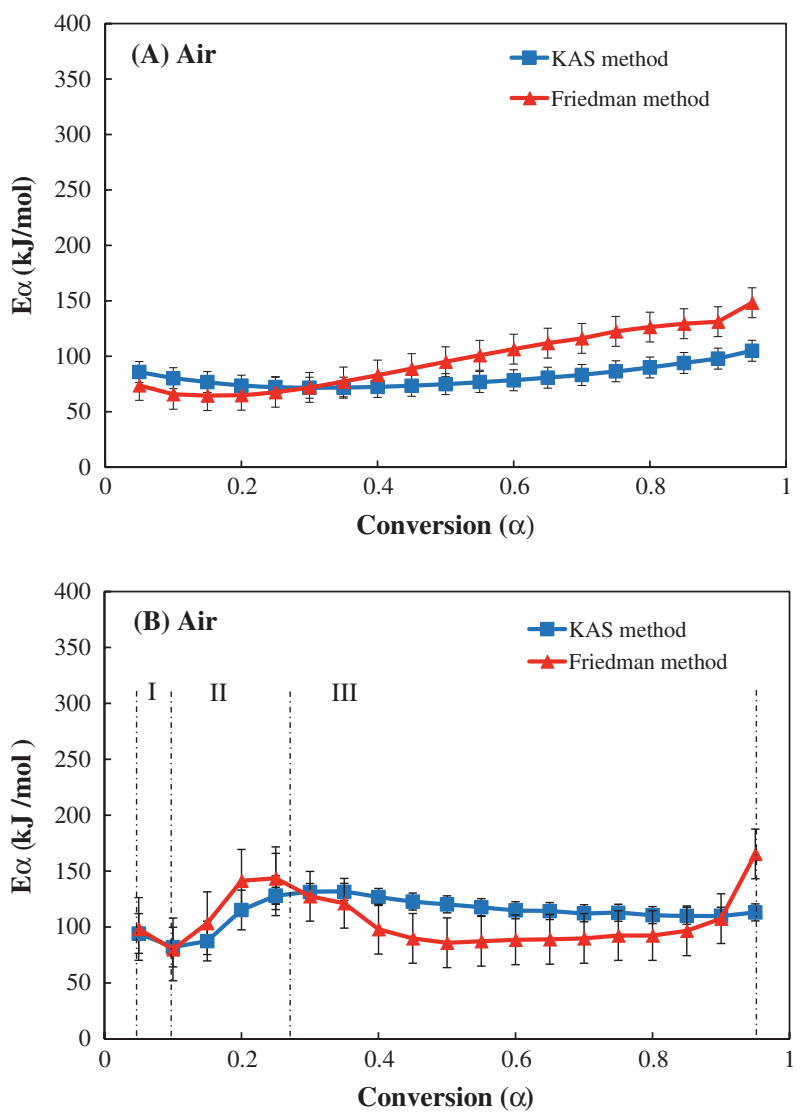

Fig. 7. The dependence of the apparent activation energy on the degree of the conversion for (A) pure PS and (B) Z-85, using the model free methods in air.

Table 4

The apparent activation energy determined by model free methods.

\begin{tabular}{lllll}
\hline Sample & $\begin{array}{l}\text { Model free } \\
\text { method }\end{array}$ & $\begin{array}{l}\text { Friedman }\left(\alpha_{m}\right) \\
(\mathrm{kJ} / \mathrm{mol})^{\mathrm{a}}\end{array}$ & $\begin{array}{l}\mathrm{KAS}\left(\alpha_{m}\right) \\
(\mathrm{kJ} / \mathrm{mol})^{\mathrm{a}}\end{array}$ & $\begin{array}{l}\text { Kissinger } \\
(\mathrm{kJ} / \mathrm{mol})\end{array}$ \\
\hline PS & Argon atmosphere & & \\
Z-85 & & $214.89 \pm 2.1$ & $236.24 \pm 3.5$ & 243.97 \\
& & $210.87 \pm 1.5$ & $232.01 \pm 1.2$ & 252.66 \\
PS & Air atmosphere & & & \\
Z-85 & & $120.02 \pm 7.6$ & $85.87 \pm 4.3$ & 61.26 \\
& & $84.15 \pm 0.29$ & $107.29 \pm 0.84$ & 102.34 \\
\hline
\end{tabular}

a The average and standard deviation values determined from activation energies for conversion correspond to the temperature DTG peak at different heating rates $\left(10,15,20\right.$, and $\left.30^{\circ} \mathrm{C} / \mathrm{min}\right)$.

mechanisms presented in the literature. It is worth noting that the experimental values of $E$ may not be representative of any individual reaction step of the decomposition. Therefore, the term apparent activation energy is used [55,61].

\subsubsection{Experiments in argon}

The dependence of the apparent activation energy on the extent of conversion for the thermal decomposition of pure PS and Z-85 in argon is shown in Fig. 6. The results from the two methods based on the integral form of the rate equation, i.e. the OFW and KAS methods, are very close and the OFW method was, therefore, dropped [55]. Thermal decomposition of the pure PS has been studied by different researchers [37,57-60,62-64]. It has been suggested that thermal decomposition process of PS initiates at weak link sites, such as hydroperoxy and peroxy groups, always present within the polymer chain $[57,60]$. Once all weak link sites have 

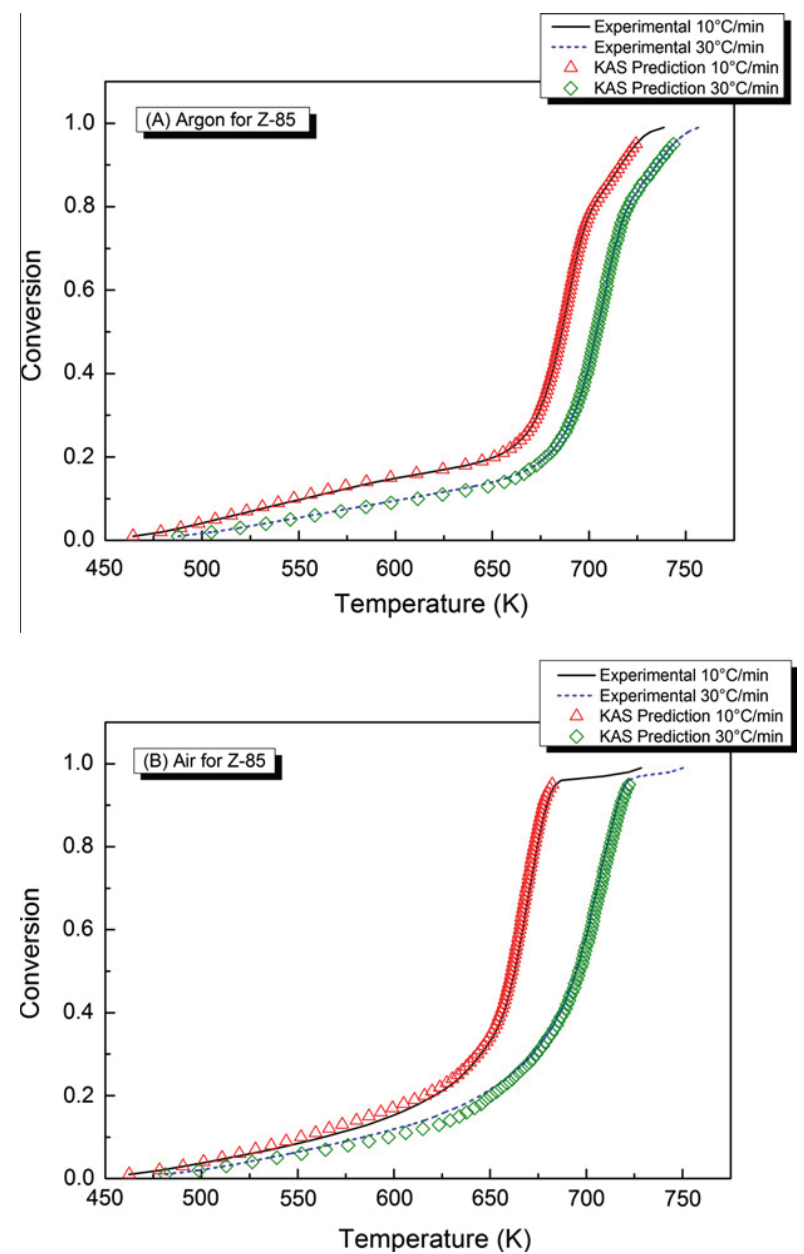

Fig. 8. Comparison of experimental data and KAS predictions for non-isothermal conditions for: (A) argon atmosphere and (B) air atmosphere.

Table 5

ARD (\%) values for predication the non-isothermal experiments.

\begin{tabular}{lll}
\hline Heating rate $\left({ }^{\circ} \mathrm{C} / \mathrm{min}\right)$ & Argon atmosphere & Air atmosphere \\
\hline 10 & 0.30 & 0.29 \\
15 & 0.32 & 0.45 \\
20 & 0.46 & 0.30 \\
30 & 0.34 & 0.70 \\
\hline
\end{tabular}

reacted out, the decomposition of the polymer continues through a random scission process, also called "unbuttoning" process $[57,59,60]$.

As can be seen in Fig. 6A, the variations of $E_{\alpha}$ with $\alpha$ are small for pure PS in argon atmosphere, which likely indicates a single rate limiting decomposition step over the entire reaction duration. The deviations are within the conventionally accepted $10 \%$ level of error in activation energy due to experimental uncertainties and approximations in the calculation method [30,31]. The average activation energy for the rate limiting step is $235.84 \pm 6.7 \mathrm{~kJ} / \mathrm{mol}$ by KAS method and $225.75 \pm 13.45 \mathrm{~kJ} / \mathrm{mol}$ by Friedman method (s. also Fig. 6A). The observed activation energy is similar to values ( $\approx 200 \mathrm{~kJ} / \mathrm{mol}$ ) reported by other authors for the decomposition of PS in inert atmospheres calculated with model free methods [37,57-59]. The rate limiting reaction step is attributed to one of the steps of the scission process. The weak links seem not to play a big role in the decomposition of pure PS, since the activation energy reported for the decomposition via monomolecular hydroperoxide groups is lower. The values given vary from $25-30 \mathrm{~kJ} / \mathrm{mol}[58]$ to $80-125 \mathrm{~kJ} / \mathrm{mol}[37,57,65] . E_{\alpha}$ at the beginning of decomposition of kneaded PS is lower ( $\approx 65 \mathrm{~kJ} / \mathrm{mol}$ ), suggesting that peroxy and/ or hydroperoxy groups are introduced by the kneading process. The activation energy for the decomposition reaction of stearic acid remains also fairly constant over the entire reaction progress and the average value of $83 \mathrm{~kJ} / \mathrm{mol}$ is similar to values reported in the literature [66].

Fig. $6 \mathrm{~B}$ displays $E_{\alpha}$ vs. $\alpha$ for the Z-85 sample using the different model free methods in argon atmosphere. Three decomposition stages (I, II, III) can be distinguished in Fig. 6B. At the beginning of the reaction (stage $\mathrm{I}$ ), the apparent activation energy $(\sim 55 \mathrm{~kJ} / \mathrm{mol})$ is considerably lower than for PS in argon $(\sim 230 \mathrm{~kJ} /$ mol) and shows a decreasing tendency. The decomposition of SA is partly responsible for this decrease. The major factor, however, for the low value is the enhanced concentration of weak links in the PS due to the vigorous mixing at high temperature $[67,68]$. The mixing step is performed in air, which is advantageous for the formation of peroxide and hydroperoxide groups. The formation of weak links seems to be more vigorous in the presence of oxide particles than in pure PS (c.f. Fig. 6A and B). The weak link mechanism dominates the decomposition kinetics up to $\alpha=0.1$. The initial value of the activation energy is thus composed from the contribution of two parallel processes, i.e., SA evaporation and PS decomposition through the weak link processes.

For $\alpha>0.1$ (stage II) the activation energy increases steadily, reaching a maximum of $270.19 \mathrm{~kJ} / \mathrm{mol}$ for the Friedman method $(\alpha \approx 0.2)$ and $219.91 \mathrm{~kJ} / \mathrm{mol}$ for the KAS method $(\alpha \approx 0.3)$. Such an increase is characteristic of two or more competing parallel reactions [34,36]. The KAS value remains constant (stage III) for the remaining reaction progress, except a small increase at $\alpha=0.8$, and is close to the values reported for the scission mechanism in polystyrene $[37,57,58]$. The latter, therefore, would be the reaction competing with SA decomposition and weak link reactions until they react out of the system. The Friedman curve beyond $\alpha=0.3$ decreases by $60 \mathrm{~kJ} / \mathrm{mol}$ before increasing again at $\alpha=0.6$. Although only slightly above the $10 \%$ uncertainty level, the observed decrease may indicate another set of competing reactions, most likely among the steps in the scission process. Both activation energy curves show an increase and a maximum towards the completion of the reaction. The corresponding temperature correlates with the onset of the shoulder around $450{ }^{\circ} \mathrm{C}$ in the differential TGA curve (see Fig. 3B).

Transport processes have not been considered in the above discussion. The observed development of the activation energy can be explained without invoking transport of either heat or mass to contribute to the rate limiting processes. The activation energy for transport of break-down products increases with the molecular weight of the breakdown product, but typical values for $E_{\alpha}$ are between 2 and $20 \mathrm{~kJ} / \mathrm{mol}$ [69]. Mass transport alone is, therefore, never rate limiting in the present case. It is, however, not impossible that mass transport may locally be rate limiting and contribute to the low activation energy at the beginning of the decomposition or to the duration of the decomposition where $E_{A}$ falls below the value typical for PS.

\subsubsection{Decomposition kinetics in air by KAS and Friedman methods}

The thermal decomposition process in air changes the reaction path of the thermal decomposition [57,59,60]. As shown in Fig. 7A, the activation energy does not vary much and is in the range of the values given for the thermo-oxidative decomposition of PS $[37,57,59,60]$. The slight increase for the Friedman derived values may point to competition by the scission mechanism with advancing reaction mechanism.

The initial activation energy (stage I) for Z-85 (Fig. 7B), i.e. $79.90 \mathrm{~kJ} / \mathrm{mol}$ for the Friedman method and $87.10 \mathrm{~kJ} / \mathrm{mol}$ for KAS 
method, is slightly lower compared to the value for pure PS. After a small decrease $E_{\alpha}$ starts $(\alpha \sim 0.15)$ to increase and reaches a maximum of $143.6 \mathrm{~kJ} / \mathrm{mol}$ for the Friedman method respectively $127.9 \mathrm{~kJ} / \mathrm{mol}$ for the KAS method (stage II). The competitive reaction, leading to the increase the activation energy, is probably the scission mechanism. In order for the thermo-oxidation to work, oxygen has to be present at the reaction site. The diffusion of oxygen in the feedstock may be retarded by the presence of the powder particles. At the beginning of the reaction the weak links introduced during kneading of the feedstock react, then follows a short time span (stage II) where oxygen concentration inside the sample is still low and some of the polymer decomposition proceeds by the scission mechanism. For $\alpha>0.15, E_{\alpha}$ decreases and for the Friedman method, reaches again the initial value typical for the thermo-oxidative mechanism.

A feature, present in the conversion rate curves obtained with Z-85 in air (Fig. 5B), is the small secondary maximum towards the end of the reaction (Fig. 7B) corresponding to a temperature of $450-460{ }^{\circ} \mathrm{C}$. Bourbigot et al. [58] demonstrated that the associated weight loss is due to the oxidation of char, a potential product of hydroperoxide decomposition during the initial phases of PS decomposition. The shoulder also observed around $450{ }^{\circ} \mathrm{C}$ in conversion rate curves of the experiments in argon atmosphere (Fig. 3B) may be due to the same phenomenon. The oxygen, however, has to come from a source different than the atmosphere, the possibility either being the zirconia particles or the weak links introduced during kneading of the feedstock. The fact that these high temperature features are absent in the pure PS under air may indicate that independent of atmosphere char formation requires the presence of the ceramic substrate.

\subsubsection{Decomposition kinetics by Kissinger method}

The Kissinger method has been used to determine the apparent activation energy for the temperature corresponding to the maximum weight loss rate. The values correspond approximately to the activation energies at $\alpha_{m}$ for the Friedman respectively the KAS methods (Table 4).

\subsection{Predictive power}

A major goal of the present kinetic analysis is to evaluate the predictive potential of the model free methods for debinding processes. We tested the latter by using $T_{\alpha}$ and $E_{\alpha}$ values (KAS method) obtained in a non-isothermal run with a heating rate of $10^{\circ} \mathrm{C} / \mathrm{min}$ to predict the weight loss for a heating rate of $30^{\circ} \mathrm{C} / \mathrm{min}$ and vice versa (Fig. 8). The fit between calculated and measured conversion values as the function of temperature is excellent as testified by very low ARD's (Table 5).

\section{Conclusion}

The present work has shown that for thin thermoplastic composites constituted of zirconia and a PS-SA mixture, the debinding rate may entirely be described by the kinetics of the decomposition reaction of the polymers present in the feedstock, without taking into account transport processes. The difference between the decomposition of the pure polymers and the polymers present in the thermoplastic composite is due to the mixing process. The mechanical treatment increases the amount of weak links in the polymer, which are responsible for enhanced decomposition at lower temperatures and the formation of char as reaction product. In agreement with other authors is the observation that zirconia seems to have no catalytic effect on the decomposition reactions [25]. The different model free kinetic models (Friedman, KAS) tested give consistent results and the activation energies extracted from them allow reliable prediction of the debinding kinetics for arbitrary heating rates.

\section{Acknowledgements}

The authors would like to thank Mr. Saeed Abbasion at Laboratory for Building Science and Technology (Empa) for his kind help in the treatment of the kinetic data.

\section{References}

[1] Park SK, Ahn J-H, Kim TS. Performance evaluation of integrated gasification solid oxide fuel cell/gas turbine systems including carbon dioxide capture. Appl Energy 2011;88:2976-87.

[2] Will J, Mitterdorfer A, Kleinlogel C, Perednis D, Gauckler LJ. Fabrication of thin electrolytes for second-generation solid oxide fuel cells. Solid State Ionics 2000;131:79-96.

[3] Riegel J, Neumann H, Wiedenmann HM. Exhaust gas sensors for automotive emission control. Solid State Ionics 2002;152-153:783-800.

[4] Haile SM. Fuel cell materials and components. Acta Mater 2003:51:5981-6000.

[5] Dahl P, Kaus I, Zhao Z, Johnsson M, Nygren M, Wiik K, et al. Densification and properties of zirconia prepared by three different sintering techniques. Ceram Int 2007;33:1603-10.

[6] De Souza S, Visco SJ, De Jonghe LC. Reduced-temperature solid oxide fuel cell based on YSZ thin-film electrolyte. J Electrochem Soc 1997;144:L35-7.

[7] Xin X, Lü Z, Huang X, Sha X, Zhang Y, Su W. Anode-supported solid oxide fuel cell based on dense electrolyte membrane fabricated by filter-coating. J Power Sources 2006;159:1158-61.

[8] Du Y, Sammes NM. Fabrication of tubular electrolytes for solid oxide fuel cells using strontium- and magnesium-doped $\mathrm{LaGaO}_{3}$ materials. J Eur Ceram Soc 2001;21:727-35

[9] Clemens F, Graule T, Ttp. Thin wall ceramic tubes by extrusion of thermoplastic $\mathrm{ZrO}(2)$ compounds. Euro Ceram, vii, Pt 1-3. Stafa-Zurich: Trans Tech Publications Ltd; 2002. p. 425-8.

[10] Du Y, Sammes NM, Tompsett GA, Zhang D, Swan J, Bowden M. Extruded tubular strontium- and magnesium-doped lanthanum gallate, gadoliniumdoped ceria, and yttria-stabilized zirconia electrolytes. Mechanical and thermal properties. J Electrochem Soc 2003;150:A74-8.

[11] Trunec M. Fabrication of zirconia- and ceria-based thin-wall tubes by thermoplastic extrusion. J Eur Ceram Soc 2004;24:645-51.

[12] Sammes NM, Du Y, Bove R. Design and fabrication of a $100 \mathrm{~W}$ anode supported micro-tubular SOFC stack. J Power Sources 2005;145:428-34.

[13] Sammes NM, Du Y. Fabrication and characterization of tubular solid oxide fuel cells. Int J Appl Ceram Technol 2007;4:89-102.

[14] Jardiel T, Sotomayor ME, Levenfeld B, Várez A. Optimization of the processing of 8-YSZ powder by powder injection molding for SOFC electrolytes. Int J Appl Ceram Technol 2008;5:574-81.

[15] Jardiel T, Levenfeld B, Jiménez R, Várez A. Fabrication of 8-YSZ thin-wall tubes by powder extrusion moulding for SOFC electrolytes. Ceram Int 2009;35:2329-35.

[16] Lewis JA. Binder removal from ceramics. Annu Rev Mater Sci 1997;27:147-73.

[17] Shi Z, Guo ZX, Song JH. A diffusion-controlled kinetic model for binder burnout in a powder compact. Acta Mater 2002;50:1937-50.

[18] Khoong LE, Lam YC, Chai JC, Ma J, Jiang L. Modeling of mass transfers in a porous green compact with two-component binder during thermal debinding. Chem Eng Sci 2009;64:2837-50.

[19] Shende RV, Lombardo SJ. Determination of binder decomposition kinetics for specifying heating parameters in binder burnout cycles. J Am Ceram Soc 2002;85:780-6.

[20] Liau LCK, Viswanath DS. Thermal degradation of poly(vinylbutyral)/ceramic composites: a kinetic approach. Ind Eng Chem Res 1998;37:49-57.

[21] Liau LCK, Liau JY, Chen YT. Study of the composition effect of glass ceramic and silver on poly(vinyl butyral) thermal degradation with thermogravimetric analysis. J Appl Polym Sci 2004;93:2142-9.

[22] Liau LCK, Chiu CC. Optimal heating strategies of polymer binder burnout process using dynamic optimization scheme. Ind Eng Chem Res 2005:44:4586-93.

[23] Liau LCK, Hsieh YP. Kinetic analysis of poly(vinyl butyral)/glass ceramic thermal degradation using non-linear heating functions. Polym Degrad Stab 2005;89:545-52.

[24] Lombardo SJ, Yun JW, Krueger DS. The influence of binder degradation kinetics on rapid binder removal cycles. In: Bansal NP, Singh JP, Schneider H, editors. Innovative processing and synthesis of ceramics, glasses and composites, vol. viii. Westerville: Amer Ceramic Soc; 2005. p. 191-201.

[25] Liau LCK, Chien YC. Kinetic investigation of $\mathrm{ZrO}_{2}, \mathrm{Y}_{2} \mathrm{O}_{3}$, and $\mathrm{Ni}$ on poly(vinyl butyral) thermal degradation using nonlinear heating functions. J Appl Polym Sci 2006;102:2552-9.

[26] Yun JW, Lombardo SJ, Krueger DS, Scheuer P. Effect of decomposition kinetics and failure criteria on binder-removal cycles from three-dimensional porous green bodies. J Am Ceram Soc 2006;89:176-83.

[27] Aggarwal G, Park SJ, Smid I, German RM. Master decomposition curve for binders used in powder injection molding. Metall Mater Trans A 2007;38:606-14. 
[28] Chen C-C, Liau LC-K, Jung G-B, Chan SH. Composition effects in YSZ electrolyte tapes for solid oxide fuel cells fabricated by tape casting. ECS Trans 2007;7: 2161-5.

[29] Vyazovkin S, Wight CA. Kinetics in solids. Annu Rev Phys Chem 1997;48: $125-49$.

[30] Vyazovkin S, Wight CA. Isothermal and non-isothermal kinetics of thermally stimulated reactions of solids. Int Rev Phys Chem 1998;17:407-33.

[31] Vyazovkin S, Wight CA. Model-free and model-fitting approaches to kinetic analysis of isothermal and nonisothermal data. Thermochim Acta 1999;340341:53-68.

[32] Criado JM, Morales J. Defects of thermogravimetric analysis for discerning between first order reactions and those taking place through the AvramiErofeev's mechanism. Thermochim Acta 1976;16:382-7.

[33] Vyazovkin SV, Lesnikovich AI. An approach to the solution of the inverse kinetic problem in the case of complex processes. Part 1. Methods employing a series of thermoanalytical curves. Thermochim Acta 1990;165:273-80.

[34] Vyazovkin S. A unified approach to kinetic processing of nonisothermal data. Int J Chem Kinet 1996;28:95-101.

[35] Vyazovkin S. Conversion dependence of activation energy for model DSC curves of consecutive reactions. Thermochim Acta 1994;236:1-13.

[36] Vyazovkin SV, Goryachko VI, Lesnikovich AI. An approach to the solution of the inverse kinetic problem in the case of complex processes. Part III. Parallel independent reactions. Thermochim Acta 1992;197:41-51.

[37] Vyazovkin S, Dranca I, Fan X, Advincula R. Kinetics of the thermal and thermooxidative degradation of a polystyrene-clay nanocomposite. Macromol Rapid Commun 2004;25:498-503.

[38] Joseph H F. The effect of heating rate upon the coupling of complex reactions. I. Independent and competitive reactions. Thermochim Acta 1980;37:225-38.

[39] Agrawal RK. Kinetic analysis of complex reactions. J Therm Anal Calorim 1986;31:1253-62.

[40] Kissinger HE. Reaction kinetics in differential thermal analysis. Anal Chem 1957;29:1702-6.

[41] Akahira T, Sunose T. Method of determining activation deterioration constant of electrical insulating materials. Res Rep Chiba Inst Technol (Sci Technol) 1971:16:22-31.

[42] Ozawa T. A new method of analyzing thermogravimetric data. Bull Chem Soc Jpn 1965;38:1881-6.

[43] Flynn JH, Wall LA. A quick direct method for determination of activation energy from thermogravimetric data. J Polym Sci Part B - Polym Lett 1966;4: 323-8.

[44] Coats AW, Redfern JP. Kinetic parameters from thermogravimetric data. Nature 1964;201:68-9.

[45] Urbanovici E, Segal E. Some problems concerning the temperature integral in non-isothermal kinetics: Part 3. An approximation of the temperature integral through integration over small temperature intervals. Thermochim Acta 1992;203:153-7.

[46] Flynn JH. The 'temperature integral' - its use and abuse. Thermochim Acta 1997;300:83-92

[47] Cai J, Yao F, Yi W, He F. New temperature integral approximation for nonisothermal kinetics. AIChE J 2006;52:1554-7.

[48] Doyle CD. Kinetic analysis of thermogravimetric data. J Appl Polym Sci 1961;5: 285-92.

[49] Budrugeac P. Critical considerations on the Augis and Bennett method for evaluating the crystallization activation energy by means of non-isothermal data. J Non-Cryst Solids 2011;357:1101-5.
50] Friedman HL. Kinetics of thermal degradation of char-forming plastics from thermogravimetry. Application to a phenolic plastic. J Polym Sci Part C: Polym Symp 1964;6:183-95

[51] Budrugeac P. Thermal degradation of glass reinforced epoxy resin and polychloroprene rubber: the correlation of kinetic parameters of isothermal accelerated aging with those obtained from non-isothermal data. Polym Degrad Stab 2001;74:125-32.

[52] Budrugeac P, Homentcovschi D, Segal E. Critical considerations on the isoconversional methods III. On the evaluation of the activation energy from non-isothermal data. J Therm Anal Calorim 2001;66:557-65.

[53] Budrugeac P, Segal E. Some methodological problems concerning nonisothermal kinetic analysis of heterogeneous solid-gas reactions. Int J Chem Kinet 2001;33:564-73.

[54] Sbirrazzuoli N. Is the Friedman method applicable to transformations with temperature dependent reaction heat? Macromol Chem Phys 2007:208:1592-7.

[55] Vyazovkin S, Burnham AK, Criado JM, Pérez-Maqueda LA Popescu C Sbirrazzuoli N. ICTAC kinetics committee recommendations for performing kinetic computations on thermal analysis data. Thermochim Acta 2011;520: $1-19$.

[56] Senum GI, Yang RT. Rational approximations of the integral of the Arrhenius function. J Therm Anal 1977;11:445-7.

[57] Peterson JD, Vyazovkin S, Wight CA. Kinetics of the thermal and thermooxidative degradation of polystyrene, polyethylene and poly(propylene). Macromol Chem Phys 2001;202:775-84

[58] Bourbigot S, Gilman JW, Wilkie CA. Kinetic analysis of the thermal degradation of polystyrene-montmorillonite nanocomposite. Polym Degrad Stab 2004;84:483-92.

[59] Chen K, Vyazovkin S. Mechanistic differences in degradation of polystyrene and polystyrene-clay nanocomposite: thermal and thermo-oxidative degradation. Macromol Chem Phys 2006;207:587-95.

[60] Vyazovkin S, Sbirrazzuoli N. Isoconversional kinetic analysis of thermally stimulated processes in polymers. Macromol Rapid Commun 2006;27:1515-32.

[61] Vyazovkin S. Model-free kinetics. J Therm Anal Calorim 2006;83:45-51.

[62] Lehrle RS, Peakman RE, Robb JC. Pyrolysis-gas-liquid-chromatography utilised for a kinetic study of the mechanisms of initiation and termination in the thermal degradation of polystyrene. Eur Polymer J 1982;18:517-29.

[63] Cameron GG, Bryce WAJ, McWalter IT. Thermal degradation of polystyrene-5. Effects of initiator residues. Eur Polymer J 1984;20:563-9.

[64] Costa L, Camino G, Guyot A, Bert M, Clouet G, Brossas J. The effect of the chemical structure of chain ends on the thermal degradation of polystyrene. Polym Degrad Stab 1986;14:85-93.

[65] Emanuel' NM, Buchachenko AL. Chemical physics of polymer degradation and stabilization. Utrecht, The Netherlands: VNU Science Press; 1987.

[66] Jaw KS, Hsu CK, Lee JS. The thermal decomposition behaviors of stearic acid, paraffin wax and polyvinyl butyral. Thermochim Acta 2001;367-368:165-8.

[67] Gugumus F. Physico-chemical aspects of polyethylene processing in an open mixer. 5. Kinetics of hydroperoxide formation. Polym Degrad Stab 2000;68: 327-36.

[68] Gugumus F. Physico-chemical aspects of polyethylene processing in an open mixer. 6. Discussion of hydroperoxide formation and decomposition. Polym Degrad Stab 2000;68:337-52.

[69] Cherdhirankorn T, Harmandaris V, Juhari A, Voudouris P, Fytas G, Kremer K, et al. Fluorescence correlation spectroscopy study of molecular probe diffusion in polymer melts. Macromolecules 2009;42:4858-66. 